\title{
EPISTEMES TRANSCOMPLEJOS DE LOS SABERES PATRIMONIALES EN LA TRANSMODERNIDAD: MIRADAS RIZOMÁTICAS
}

\author{
TRANSCOMPLEX EPISTEMES OF HERITAGE KNOWLEDGE IN \\ TRANSMODERNITY: RHIZOMATIC INSIGHTS
}

\author{
Milagros Elena Rodríguez \\ Universidad de Oriente, República Bolivariana de Venezuela
}

Aceptado: 15 de abril de 2020

\section{RESUMEN}

Con la hermenéutica comprensiva, diatópica y ecosófica como transmétodo de construcción teórica, se analizan ejes teóricos epistémicos de los saberes patrimoniales enmarcados en la transmodernidad; comprendiendo la interioridad de los saberes patrimoniales, la cultura, transcomplejidad, patrimonio cultural, transmodernidad, Educación Patrimonial Transcompleja (EPT) y la ecosofía. En el rizoma final los saberes patrimoniales y la información transmitida no captan todo el significado, la relación de los saberes patrimoniales entre sujetos es intersubjetiva, es urgente una descolonización de ellos y sus consideraciones basadas en la ciudadanía y su identidad aceptando que dichos saberes entrañan la complejidad. La EPT, configura un proceso dinámico, emergente, religante y relativo, donde se complejiza el patrimonio cultural desde aprender, desaprender y reaprender siguiendo las huellas de los saberes patrimoniales.

Palabras clave: transcomplejidad, transmodernidad, saberes patrimoniales.

\begin{abstract}
With comprehensive, diatopic and ecosophic hermeneutics as a transmethod of theoretical construction, epistemic theoretical axes of heritage knowledge framed in transmodernity are analyzed; understanding the interiority of heritage knowledge, culture, transcomplexity, cultural heritage, transmodernity, Transcomplex Heritage Education and ecosophy. In the final rhizome the patrimonial knowledge and the transmitted information do not capture all the meaning, the relationship of the patrimonial knowledge between subjects is intersubjective, a decolonization of them and their considerations based on citizenship and their identity is urgent, accepting that said knowledge involves complexity. Transcomplex Heritage Education configures a dynamic, emergent, related and relative process, where cultural heritage becomes more complex from learning, unlearning and relearning following the traces of heritage knowledge.
\end{abstract}

Keywords: transcomplexity, transmodernity, heritage knowledge.

Este es un artículo Open Access bajo la licencia Creative Commons AtribuciónNoComercial-Compartirlgual 4.0

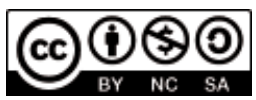




\section{Rizoma inicial: transmetodología de la indagación y los saberes patrimoniales modernistas}

Latinoamérica es producto de un mestizaje; no se puede obviar esta realidad dentro de nuestro patrimonio cultural, por ello se necesita con urgencia la actualización de maestros, educadores y ciudadanos que manejen -desvestidos de subjetividad- las diferencias que convergen en nuestra ciudadanía. Es menester entonces, la educación patrimonial que emerge en el hábitat popular, en las comunidades y en los grupos populares; esto se completa con la educación patrimonial en las instituciones educativas, donde se ‘abracen' ciudad y escuela. Es decir, los saberes patrimoniales representan todos los asuntos patrimoniales y lo que se concibe de ellos, incluyendo la educación patrimonial (Rodríguez, 2017).

La educación patrimonial en el proyecto modernista es soslayadora y hereda todos los males de la invasión a este continente y las secuelas de la colonización del saber y del poder (Rodríguez, 2018a). En Venezuela, hay que reconocer que pese a los avances en política de cultura, diversidad cultural y patrimonio cultural, no existe en los currículos de primaria ni de secundaria, asignaturas que propendan el estudio del patrimonio cultural; excepto actividades extracurriculares alrededor de la cultura. Pese a los reconocimientos en la legalidad, el proyecto modernista tiene serios rezagos junto a la globalización y la marca en la cultura, diversidad cultural y patrimonio cultural (Rodríguez, 2015a, 2015b, 2017). En contraposición, el proyecto que va al rescate de las víctimas de la modernidad y tan estudiado por investigadores de la talla de Enrique Dussel en la transmodernidad. En tal sentido, la idea o noción de transmodernidad surgió con «la conciencia de que, para intentar hacer cualquier abstracción o formalización de la realidad pensada en términos no modernos, se trataba siempre de partir de las historias negadas, encubiertas, excluidas y condenadas al olvido por la modernidad» (Bautista, 2014, p. 57).

La transmodernidad, es el espacio de la educación patrimonial descolonizada. Dicho espacio como proyecto de descolonización de las mentes y del conocimiento es la única forma que tenemos para salir del marco categorial del pensamiento moderno. En buena cuenta, «es cuando podemos situarnos existencialmente desde estos otros horizontes de cosmovisión contenidos en las culturas vivas de nuestros pueblos originarios y que la modernidad, con sus procesos de modernización, quiere seguir destruyendo» (Bautista, 2014, p. 279).

Venezuela tiene serios intentos de descolonización, proceso que se fragua en las acciones que de manera deliberada en la educación deja su secuela. Aún tenemos una educación enmarcada en un proyecto modernista bajo la colonización del poder y la colonialidad del saber. No se trata de dar un barrido a la educación patrimonial de la modernidad. Como lo señala Dussel (2005), una futura cultura transmoderna, que asume los momentos positivos de la modernidad, pero evaluados con criterios distintos desde otras culturas milenarias, tendrá una pluriversidad rica y será fruto de un auténtico diálogo intercultural, que debe tomar claramente en cuenta las asimetrías existentes. Por eso, la conciencia de la transculturización y globalización debe estar presente en la educación patrimonial provenir, pero con el propósito de ir al rescate de las culturas olvidadas y soslayadas que nos hacen trastocar nuestra identidad como venezolanos y llegar a ser lo que somos.

De la transmodernidad, se entiende la posibilidad de trascender hasta la valoración de nuestras culturas; a lo que la modernidad enterró, desvalorizó, a la pérdida de verdaderos patrimonios y tantas culturas desaparecidas. Tantos aborígenes eliminados y sus culturas; hasta el nombre de nuestro país, impuesto como el nombre del 
continente; y es que no se puede olvidar que mucha de nuestra cultura ha sido transculturizada; pero en la transmodernidad, que en el contexto americano tiene muchos investigadores y defensores. Se puede decir que las políticas escritas en las leyes venezolanas están ubicadas en un proyecto transmoderno. Ahora, ¿quiénes serán los que las apliquen? La respuesta, representa un camino largo de muchos desafíos.

Es preciso informar que la decolonialidad que se propende en la transmodernidad es planetaria; no tiene un sesgo epistémico, no se trata de excluir al Norte o a Europa para hacer valer al Sur, no. Es notorio, en primer lugar, reconocer que la modernidad/colonialidad es excluyente, «es incapaz de ofrecer nuevas alternativas políticas, metodológicas y teóricas claras, ante la multiplicidad de tensiones que en ella constelan. Se requiere que ésta, ofrezca la necesidad de construir procesos políticos emancipadores» (Ocampo, 2018, p. 16). Estos propósitos políticos emancipadores no son posibles sobre el yugo moderno-postmoderno; no hay posibilidad de la inclusión de lo excluido de la propia modernidad, menos en una colonialidad que está viva actualmente y en marcha con la globalización y la hegemonía del Norte.

Por otro lado, la educación patrimonial es un espacio que apenas comienza a perfilarse sin estar definida ni siquiera como obligatoria en las instituciones educativas; no obstante, sí hay serios pasos del reconocimiento de nuestra cultura. Pero, ¿qué pasa con la preservación, con el reconocimiento de patrimonios culturales de nuestros aborígenes, del hábitat popular, de las comunidades olvidadas lejos de las capitales de los Estados de Venezuela? Pues, seguir reconociendo patrimonios culturales, como las obras que dejaron los invasores, supuestos colonizadores (erradamente denominados como tales); es seguir perpetuando la transculturización, la imposición modernista y ahora capitalista; es decir, la dominación que nos hace sentir menos que los demás.

De todo esto debe encargarse la educación patrimonial. Dedicarse a ir a las comunidades más apartadas en búsqueda de culturas, posibles patrimonios intangibles de tantos cultores valiosos; y para eso, hace falta un verdadero registro de ellas: el Estado Sucre, en Venezuela, por ejemplo. En el mismo sentido, si los profesionales, científicos, políticos se identifican con el patrimonio cultural, desde sus discursos y lugares donde se desenvuelven pueden enseñar de patrimonio cultural y hacer educación patrimonial. Sin menospreciar la ayuda valiosísima, por ejemplo, de los consejos comunales, el poder comunal debe ir a la raíz de las culturas. Debe hacerse una verdadera revolución cultural que llegue a la gente, que logre el cambio de pensamiento; una ciudadanía empoderada yendo al rescate de su identidad.

Se trata de aprender como lo argumenta Santos (2006): «Sur entendido como una metáfora del sufrimiento humano causada por el capitalismo, encarno mi objetivo de reinventar una emancipación social» (p. 37). Esta emancipación a la que se refiere también es educativa. Es importante discernir la decolonialidad que devela la contra-hegemonía del Norte sobre el Sur; desde luego que hay una incompatibilidad entre la razón metonímica con la emancipación del mundo, su decolonialidad. Por lo que también propone «ampliar el presente para incluir en él muchas más experiencias» (Santos, 2006, p. 20).

Por otro lado, en la transmodernidad, la visión transcompleja se caracteriza por la profundización de las relaciones y de ver el todo del conocimiento, no importa si viene de las ciencias o de los saberes populares; combina muy bien la transcomplejidad con las nuevas formas de su organización, salvaguarda y hacia nuevas 
formas de concebir la cultura desde la transmodernidad; por ende, la educación patrimonial necesita de la unidad del conocimiento, de la transdiciplinariedad, de la unión de las ciencias y también de los saberes cotidianos.

Se requiere una verdadera educación patrimonial, y con ella, un discurso alejado de la tecnicidad y la cientificidad, un discurso para todos, donde los unos y los otros se mezclen y se entiendan. Construir una educación que se aleje de las áreas disciplinarias requiere de la coloquialidad, cotidianidad y convivencia del saber. Desde luego, en las instituciones educativas no se trataría, ya que la cultura la aprueban los científicos, pero ella existe, y de esa manera debe ser aceptada y practicada por el ciudadano para que se identifique con ella; es así que fluye el patrimonio cultural.

En esta investigación, que transciende las metodologías y va a más allá de una transmetodologia, se usa la hermenéutica comprensiva, diatopica y ecosófica como transmétodo de construcción teórica, para visionar ejes epistémicos transcomplejos de los saberes patrimoniales enmarcados en la transmodernidad; la tarea no es explicar lo exterior, aquello en lo que la experiencia se expresa, sino comprender la interioridad de la que ha nacido; lo relativo a la educación patrimonial, a todos sus saberes patrimoniales y a la de cada una de las categorías como saberes patrimoniales, cultura, transcomplejidad, transmodernidad y ecosofía, entre otras. En este caso, hermenéutica comprensiva, diatopica y ecosófica, que permite a esta investigadora interpelar los territorios temáticos del conocimiento, la imaginación creadora, la actitud transvisionaria, la irreverencia frente a lo conocido, los modos de interrogar la realidad, la criticidad en el hermeneuta, la libertad de pensamiento, entre otras.

La hermenéutica diatópica consiste, segun Santos (2002), en «elevar la conciencia de la incompletud a su máximo posible participando en el diálogo, como si se estuviera con un pie en una cultura y el otro en la restante. Aquí yace su carácter diatópico» (p. 70). Es así como desde este carácter se respeta la diversidad cultural, los saberes patrimoniales, legos soterrados del hábitat popular. Siguiendo lo señalado por Santos (1998):

No sólo requiere un tipo de conocimiento diferente, sino también un proceso diferente de creación de conocimiento. Requiere la creación de un saber colectivo y participativo basado en intercambios cognitivos y emotivos iguales, un conocimiento como emancipación, más que un conocimiento como regulación. (p. 30)

Por otra parte, para Balza (2016), la hermenéutica ecosofica:

Designa asumir una perspectiva ética y comprensiva de las relaciones entre los seres humanos en su interacción cultural con el planeta tierra, lo cual deviene en una necesaria transformación de la conciencia para integrarnos a la unidad de la vida, cuya lógica es la dialógica comprensiva. (p. 44)

En ese sentido, la transmodernidad en plena consideración respalda el carácter ecosófico de la investigación. Pupo (2014), se refiere al carácter ecosófico en la reflexión sobre nuestras costumbres, el cuidado de la tierra como el patrimonio natural más grande, también la relación con las ciencias y los saberes provenientes de la cultura. 
Desde luego, para la realización de la indagación hermenéutica comprensiva, diatopica y ecosófica se pasa por niveles que están profundamente relacionados. Estos son, según Santos (2003): analítico, empírico y propositivo y según Ricoeur (1965): semántico, reflexivo y ontológico. Los niveles analítico y empírico o equivalentemente los semántico y reflexivo se cumplen desde el presente rizoma hasta el rizoma siguiente. Y el nivel propositico u ontológico donde se visionan salidas a la problemática se da el último rizoma de la indagación.

En el presente rizoma se han venido introduciendo categorías constitutivas de la indagación como rizoma, Rodríguez (2017a). La palabra rizoma que se usa de manera envolvente en los subtítulos de la presente investigación tiene una insinuación circundante, atiende a Deleuze y Guattari (1980), de manera compleja puede ser conectada con cualquier otro los razonamientos y ramas que constituyen la disposición; es una antigenealogía que rompe con las estructuras estáticas divisorias de presentar las investigaciones en las que las partes se dividen indisolublemente en un ir sin un venir. Acá la organización no responde a ningún modelo estructural o generativo.

En la transmodernidad la ecosofía tiene su realización plena; según Guattari (1996) es la ciencia del siglo XXI, «su objeto, la sabiduría para habitar el planeta. Propone pasar a la mundialización, rescatar lo local, revisar la visión que tenemos del mundo ... la clave, saber en qué forma vamos a vivir de aquí en adelante sobre este planeta» (p. 59). La sabiduría para habitar el planeta como ciudadanos éticamente responsables pasa por la condición humana que reconoce la necesidad del conocimiento y cuidado de su patrimonio cultural y natural.

Esta manera de pensar y de constituir una investigación solo es posible en la transcomplejidad donde la complejidad y transdisciplinariedad constituyen el transparadigma. González (2014) afirma que «este pensamiento transcomplejo ha construido conceptos científicos educativos muy importantes como aula mente social, emergentes educativos, metacomplejidad, deconstrucción educativa y complejidades curriculares» (p. 13). El hecho de mirar desde su complejidad, descolonización y ecología de los saberes a la educación patrimonial es de un especial valor e interés en la vida y rescate de la verdadera identidad descolonizada de los ciudadanos de Venezuela; pues el vivir desde la consciencia y el orgullo de lo que somos cobra preeminencia en el rescate de nuestra cultura en un proceso de globalización en todos los niveles. Seguimos siendo colonias reducidas a artefactos de saqueo cuando las mentes siguen colonizadas.

Más aún, el transparadigma transcomplejo como piso en la investigación es el camino viable para desentrañar la madeja tejida que sostiene el desequilibrio social e impide una evolución más expedita del asunto patrimonial ante la ciudadana y en la conformación de una verdadera identidad que esté fuera de las mentes colonizadas, en la descolonización en Venezuela. El transparadigma transcomplejo dibuja la posibilidad del decaimiento de los dogmas epistemológicos y metodológicos y da opción a una mirada de saberes patrimoniales interconectados con todas las áreas del saber y con la educación patrimonial en donde «se supera el reduccionismo que es más un modismo intelectual que una perspectiva onto-epistemológica» (Ruiz, 2008, p. 16). 


\section{Rizoma 1. La transcomplejidad como visión transparadigmática en la transmodernidad}

La transcomplejidad se asume como una cosmovisión investigativa de complementariedad que se redimensiona y se convierte en un eje totalizante y multidimensional que se fortalece en la interrelación de su componente humano y en el abordaje de una concepción de integralidad y procesalidad, que impulsa el trabajo en común y sinérgico de un equipo de investigadores. Cabe señalar que esta apreciación denota el punto nuclear en la postura de este estudio que se inspira en la multidimensionalidad de saberes, la pluralidad y la interacción, que emergen desde el trabajo en equipo y el encuentro transdisciplinario, que propugna una visión integrada y holística del acontecer investigativo.

Es necesario comprender que el patrimonio cultural, desde la figura de la educación y sus diversos contextos en la transcomplejidad, se comportan como una premisa que operativiza la construcción de conocimientos descritos en los valores, producto de la cultura y la socialización, y no en la experiencia contemporánea de los que educan y de quienes son educados.

Es decir, se hace mención a una situación que rompe los esquemas e ideologías tradicionales y se concentra en darle riqueza a los significados de argumentos, explicaciones, juicios de verdad, error, y todos aquellos elementos que generan una reestructuración cognitiva de esos valores insertos en el patrimonio cultural, hasta consolidar las relaciones metacomplejas del espacio en el acto de aprendizaje donde se da el vínculo aula-mente-social; y ese es un vínculo donde el conocimiento no se adquiere, sino que se construye mediante la representación de los valores en la realidad local y nacional; la acción de ese proceso formativo tiene, en la experiencia de la transversalidad, una triada entre movimiento-pensamiento-sentimiento, la cual responde a la necesidad de devolverle el equilibrio a los sujetos o estudiantes en el aula, que buscan mayor profundidad en las respuestas que dan los valores al patrimonio cultural; aspiran a identificar las habilidades cognoscitivas que constituyen el repertorio con que el sujeto maneja y ve su mundo, haciéndolo parte de acontecimientos que se extrapolan, interpolan o transforman, e imponen una conducta personal ante esos valores patrimoniales.

Desde el ámbito reflexivo de la complejidad, el sistema intersubjetivo del aula-mente-social, invita, en el proceso pedagógico, a crear espacios autodidácticos, desde donde sensibilizar los valores y, descubrir y reconstruir la percepción del patrimonio cultural, porque los valores que le dan razón de ser a ese patrimonio cultural son inalterables y permanentes.

Precisamente, García (2012), se refiere al patrimonio cultural venezolano dentro de un contexto de polarización política:

[que ha] distorsionado buena parte del conocimiento que sustenta los valores patrimoniales. El acceder a una visión crítica del conocimiento posibilitaría una reconciliación de los venezolanos con sus procesos culturales y el respeto a los bienes patrimoniales y a la diversidad cultural. (p. 204)

Para ello, se dan respuestas complejas y transdiciplinares propias de los saberes científicos y de los soterrados; en estos últimos convergen riquezas sustantivas de la cultura y en los primeros la reconocen en la construcción de la ciudadanía y su identidad; en una visión ecosófica llena de sabiduría para aprender a vivir en el planeta. 
Por otro lado, los estudios transcomplejos en espacios de la transmodernidad están plenamente sustentados, donde «la transmodernidad como cosmovisión episteme transfigura el entorno científico, cultural, económico, político, social y gerencial; es decir donde se desarrolla una determinada acción humana que propicie el cambio» (Guzmán, 2014, p. 128).

En Venezuela, ver las cuestiones unidas con la complejidad es un permanente desafío pues, lo que más se ve, son las cosas separadas donde cada persona hace lo suyo y separa lo que conoce de los demás conocimientos. La transcomplejidad es la producción del conocimiento a partir de la comprensión con el dialogo que lleva a hacer las cosas distintas; unidos en comunidades. No se puede concebir un mundo estancado. Tanto lo material como lo espiritual están siempre de acuerdo a la naturaleza, en constante movimiento; nada se detiene; el pensamiento siempre está fluyendo.

En perspectiva, la transcomplejidad brinda elementos de juicio que permiten avanzar en la educación patrimonial, porque ya no es vista como una educación estática, sino que conduce a su liberación. Por esta razón, en la República Bolivariana de Venezuela, una de las formas de aplicar la teoría de la transcomplejidad, en la educación patrimonial, es mediante la nueva organización que se está intentando construir en el país (así sea a manera de ensayo) para derrotar el concepto tradicional de Estado. En la multiplicidad de comunas como una nueva forma de organización política, económica y cultural, soportada en la producción, almacenamiento, transporte y distribución hasta el consumidor final, eliminando intermediarios de toda forma de bienes que contribuyan a la satisfacción de las necesidades más apremiantes del ciudadano, destacándose entre ellas la alimentación, elementos para la salud, vestir y materiales para sus viviendas, entre otros.

Esta forma organizativa, es en definitiva la que conduce al poder popular para que dirija eficazmente las riendas de la nación venezolana, como el sustituto del actual concepto de Estado, y derrote el paradigma existente en la estructura del poder burocrático que dirige la política, atándole circunstancialmente a formas de expresión, no populares. El poder popular, consecuencialmente, será el que afiance aún más la democracia participativa y protagónica; asuma la toma de decisiones y el control, desde las comunidades, para su propio bienestar tanto en la localidad como en las adyacencias. Esta expresión es el nacimiento de una nueva cultura que penetró desde la transmodernidad dentro de un pensamiento transcomplejo, que profundiza los fundamentos epistemológicos y sirve de aliciente para su implantación en otras latitudes.

\section{Rizoma 2. Epistemes transcomplejos de los saberes patrimoniales considerados en la transmodernidad}

La visión transcompleja permite ver en los saberes patrimoniales, en la educación patrimonial privilegiando su esencia cualitativa y sus interrelaciones en permanente construcción. Pero, a pesar del reconocimiento jurídicopolítico en Venezuela, de los pueblos indígenas como patrimonio cultural intangible, las acciones para su conservación han sido muy débiles y en el plano de una educación patrimonial casi inexistente.

La educación patrimonial emerge de varios contextos: no solo desde las propias comunidades indígenas, sino también desde contextos institucionales y de políticas definidas por todos los actores intervinientes. Se considera, 
que si bien puede haber flexibilidad en cuanto a un aula mente, existen procesos que ameritan de cierta formalidad, escribir y leer en su propia lengua.

Sin duda debe atenderse la formación de los docentes que orienten una educación patrimonial, muy especialmente para una educación patrimonial para los pueblos indígenas dada la complejidad de esta formación, interculturalidad, lenguas, territorios indígenas.

Por otro lado, las nuevas tecnologías tienen un papel imprescindible en los procesos educativos, y en una educación patrimonial para los pueblos indígenas es de gran ayuda. Los pueblos indígenas no están aislados son parte de ese nuevo mundo de las tecnologías de la información y de la comunicación; saben (utilizan radios, televisión, teléfonos celulares, computadoras) y deben saberlas utilizar para la permanencia y revitalización de sus patrimonios.

El diálogo como expresión transversal de diferentes puntos de vista, debe propiciar el intercambio subjetivo como expresión de acuerdos, desacuerdos, crítica y autocrítica en el encuentro con la realidad. Este diálogo se aborda desde dos puntos de vista: diálogo transdisciplinario, en este caso el conocimiento traspasa lo disciplinar y se evidencia en una nueva forma de pensar, percibir y analizar la realidad histórico-social y el papel del conocer y del conocimiento en la transformación; y diálogo de saberes, que incorpora la diversidad de puntos de vista, en este convergen acuerdos y contradicciones.

Es urgente un nuevo lenguaje, se trata de una premisa fundamental por el hecho que es la única forma en que los seres humanos establecen el diálogo. El lenguaje tiene la función de permitir ampliar el horizonte comprensivo; así como de abrir sendas por las que debe guiarse el sentido que del mundo se tiene.

En resumen, en este rizoma propositivo - de los saberes patrimoniales y su asunción, mirada e introspección compleja- se develaron consideraciones que fueron tomadas en cuenta en la transmetodología de la investigación, con visiones complejas de los saberes patrimoniales que se han venido dilucidando:

- $\quad$ En los saberes patrimoniales, la información transmitida no capta todo el significado.

- $\quad$ La relación de los saberes patrimoniales entre sujetos es intersubjetiva.

- Explorar la posibilidad de que los saberes patrimoniales sean una tentativa por crear, una descolonización de ellos y sus consideraciones; desde luego, basado en la ciudadanía y su identidad, implica ampliar la comprensión de dichos saberes.

- Los saberes patrimoniales entrañan en sí mismo la complejidad como ecosofía y sabiduría.

- Que un episteme transcomplejo de los saberes patrimoniales tenga legitimidad científica para una Educación Patrimonial Transcompleja (EPT).

$\mathrm{Al}$ respecto, Rodríguez (2018b), señala que esta configura un proceso dinámico, emergente, religante y relativo donde se complejiza el patrimonio cultural desde aprender, desaprender y reaprender siguiendo las huellas de 
los saberes patrimoniales. Como el contexto de los discursos y las prácticas en el día a día de la EPT se realizan con las mentes descolonizadas de los docentes, del ciudadano. El desarrollo de la nación va en consonancia con la EPT y sus políticas educativas patrimoniales. Por ello, la EPT como alfabetizadora del ciudadano tiene mucho sentido. Cuentan muchos profesionales analfabetos culturalmente; practicantes transculturizados que desvalorizan nuestra cultura.

Con la EPT se debe reconstruir la vida del ciudadano del país, es como llegar a valorarnos conociendo y aceptando quienes somos; es un verdadero ejercicio complejo que todos deben realizar. Los cultores, con certeza, estarían muy orgullosos de poder participar en grupos de charlas y grupos educativos; ya sea en las calles, en las comunidades, haciendo lo que saben, sienten y llegando a cada persona, sobre todo, a las nuevas generaciones. Las casas de culturas deben hacer ese papel, una verdadera revolución de enseñanza como instalar nuevos centros de formación, recreación y otros.

\section{Rizoma conclusivo}

Educar en cultura y patrimonio cultural desde nuestras instituciones venezolanas, en todos los niveles, debe ser un aspecto fundamental, porque forma parte del patrimonio nacional y como bien lo afirmó el Libertador Simón Bolívar: «un pueblo ignorante es un instrumento ciego de su propia destrucción», y si esto sucediera, se tendrían ciudadanos analfabetos política, cultural e ideológicamente, al no profundizar en el análisis de estos conceptos. Todos los docentes deben participar, desde sus conocimientos, ya que son ciudadanos y deben nutrirse de eso y hacerlo ver, sin que esto signifique menos que los conocimientos en sus áreas de estudio.

El desarrollo de una nación, debe entenderse como un proceso cultural, que depende de la identidad propia y el concepto de ciudadanía arraigado en el pueblo. El desarrollo de Venezuela, debe entenderse también como un proceso cultural, donde los ciudadanos conocen su cultura, su identidad; es lo que se debe evaluar. Es muy importante concebir el desarrollo como un proceso integrado, donde las personas se reconozcan felices siendo valoradas, y que su cultura se entienda y se respete; sin que les imponga formas de comportarse o culturas de otros. Esta es la educación que los centros educativos deben brindar a sus estudiantes para ir formando nuestra cultura; los saberes patrimoniales y el patrimonio cultural que colabore al desarrollo colectivo de las comunidades, es la visión transcompleja de los saberes patrimoniales en pleno.

El patrimonio cultural, y con ello la educación patrimonial en Venezuela, exige urgentemente respuestas en las prácticas pensadas desde la interculturalidad y la transmodernidad, y desde los saberes de las cosmovisiones de los aborígenes; se debe ir a su comunidades, aprender con ellos de su cultura; en su hábitat; en su hacer con sus cultivos, bailes, tejidos; maneras de comunicarse con la naturaleza. Todos estos saberes deben ser abrazados diatópicamente con los saberes patrimoniales del resto de la población; la comunión sin aculturización. Es importante cuidar una verdadera interculturalidad; sin que el hermano siga siendo el colonizador del aborigen.

La EPT no es idealista, es liberadora de las falsas políticas patrimoniales. No se da en una falsa política antihumana en el aborigen; en Venezuela hacer educación patrimonial es más que darle participación a su cultura; es también, mejorar su condición de vida, respetar su naturaleza. Cuando se contamina un río, se destruye con 
eso la vida en comunidad, se destruyen sus cultivos y con ello se atenta contra la condición humana del aborigen. La complejidad en la EPT exige concebir al ser humano en toda su completitud; llevarlo a su máximo desarrollo, educativo, social, espiritual y ambiental.

En la línea de la investigación titulada Educación Patrimonial Transcompleja, se aborda la educación formadora de docentes que realizarán la ejemplar tarea; que no es el objetivo en la presente investigación. Sin embargo, los docentes formados bajo la hegemonía excluyente colonial no están en la capacidad de llevar a cabo la EPT si no hay una reforma del pensamiento, otras consideraciones transepistémicas de formación (más allá de qué se conoce). En el proyecto moderno-postmoderno-colonial, en el capitalismo y en la globalización, la inclusión en la formación docente se concentra en reconocimientos de la existencia de la diversidad cultural, la diferencia, las subjetividades en general y otras; pero no conviven dentro de ellas o con ellas, siempre están en la frontera; más no en la reintervención de sus procesos formativos; ocurre lo que se llama una inclusión excluyente. Profundamente negadora de la esencia de la vida: lo complejo, lo incierto, lo indecible, entre otros. En dicha línea, es vital que se plasme en otras investigaciones la formación docente en consonancia con la EPT.

Desde luego, la complejidad hace el engranaje junto a la transdiciplinariedad. La EPT, la formación docente transcompleja con la visión de los saberes patrimoniales que propendemos en este estudio, es necesaria en las instituciones educativas; no es el mismo docente tradicional, el que sin concebir: complejidad y transdisciplinar, puede entender y valorar nuestro patrimonio cultural, y puede ver otras formas de hacer conocimientos. Se entiende que en el país ya hay muchos que hacen otras formas transversales, que usando el conocimiento no científico enseñan. Ellos pueden ser los pioneros y formadores. El científico, docente profesional en general debe tener aceptación y humildad para entender que es necesario hacer las cosas de otra manera, que hay formas nuevas y, la cultura y patrimonio cultural, también se pueden mostrar en esos escenarios. Es el ciudadano con una identidad el que hace docencia, él no es neutro y no lo debe ser. Al haber impuesto una docencia imitando a otros países y a otras culturas, antes de valorar la nuestra, se le ha hecho mucho daño al país. 


\section{Referencias}

Balza, A. (2016). Filosofía e investigación educativa desde la transcomplejidad. En Red de Investigadores de la Transcomplejidad REDIT (Ed.), Investigación transcompleja. Génesis, avances y prospectivas (pp.103-107). Caracas, Venezuela.

Bautista, J. (2014). ¿Que significa pensar desde América latina? Ediciones Akal.

Deleuze, G. y Guattari, F. (1980). Rizoma (Mil Mesetas 1980). Minuit.

Dussel, E. (2005). Transmodernidad e interculturalidad. Interpretación desde la Filosofía de la Liberación. UNAM.

García, Z. (2012). La Educación Patrimonial en Venezuela desde una Visión Latinoamericana. Una propuesta de modelo teórico [Tesis doctoral, Universidad de Sevilla]. España.

González, J. (2014). Paradigma Educativo Transcomplejo Educación del siglo XXI. Revista Ciencias Farmacia y Bioquímica, 2(1), 11-16.

Guattari, F. (1996). Las tres ecologías. Pre-Textos.

Guzmán, J. (2014). Cosmovisión emergente de la naturaleza de la realidad desde la perspectiva transcompleja. En Red de Investigadores de la transcomplejidad REDIT, Tecnología y Transcomplejidad. Universidad Bicentenaria de Aragua, Caracas, Venezuela.

Ocampo, A. (2018). La formación del profesorado y la comprensión epistemológica de la Educación Inclusiva: tensiones, permeabilidades y contingencias. Ediciones CELEI.

Pupo, R. (2014). La educación, crisis paradigmática y sus mediaciones. Sophia, Colección de Filosofía de la Educación, 17, $101-119$.

Ricoeur, P. (1965). Hermenéutica de los símbolos y reflexión filosófica. Universidad de Chile.

Rodríguez, M. (2015a). El síndrome de la globalización cultural: omnipresente, ambivalente, incierto e incognoscible. ¿Cómo afecta el patrimonio cultural? Revista Visión Educativa IUNAES, 9(20), 72-85.

Rodríguez, M. (2015b). La diversidad cultural: una riqueza vital para el patrimonio cultural, en la utopía de ser conservada y valorada. Praxis Educativa ReDIE. Revista Electrónica de la Red Durango de Investigadores Educativos, 13, 87.

Rodríguez, M. (2017). Fundamentos epistemológicos de la relación patrimonio cultural, identidad y ciudadanía: hacia una Educación Patrimonial Transcompleja en la ciudad [Tesis doctoral, Universidad Latinoamericana y el Caribe].

Rodríguez, M. (2018a). La educación patrimonial descolonizada: un espacio por construir en la transmodernidad. Praxis Educativa ReDIE. Revista Electrónica de la Red Durango de Investigadores Educativos, 18, 8-32.

Rodríguez, M. (2018b). La educación patrimonial y la formación docente desde la Transcomplejidad. TELOS Revista de Estudios Interdisciplinarios en Ciencias Sociales, 20(3), 431-449.

Ruiz, C. (2008). La universidad venezolana en una época de transición. Universidad Pedagógica Experimental Libertador-Instituto Pedagógico de Barquisimeto. http://www.ucla.edu.ve/dac/investigaci\%F3n/compendium7/Epocade Transicion.htm

Santos, B. (1998). Por una concepción multicultural de los derechos humanos. Universidad Nacional Autónoma de México.

Santos, B. (2002). Hacia una concepción multicultural de los derechos humanos. El Otro Derecho 28, 59-83.

Santos, B. (2003). Crítica de la razón indolente contra el desperdicio de la experiencia (vol. I). Para un nuevo sentido común: la ciencia, el derecho y la política en la transición paradigmática. Editorial Desclée De Brouwer, S.A.

Santos, B. (2006). Renovar la teoría crítica y reinventar la emancipación social. CLACSO.

\section{Milagros Elena Rodríguez}

Ph. D. en Ciencias de la Educación. Doctora en Patrimonio Cultural. Doctora en Innovaciones Educativas. Magister Scientiaurum en Matemáticas. Licenciada en Matemática. Docente Investigadora titular a dedicación exclusiva del Departamento de Matemáticas, docente de postgrado en Educación. Postgrado en Administración y postgrado en Biología de la UDO. Es tutora de estudiantes de pregrado y postgrado. Cuenta con más de cien investigaciones arbitradas a nível nacional e internacional. Líneas de investigación: transepistemologia de las ciencias, educación-transepistemologia transcomplejas, economía-administración-gestión-y finanzas transcomplejas, análisis de regresión y variables Dummy, matemática-cotidianidad-y pedagogía integral, didáctica transdisciplinaria de las ciencias y desarrollo humano, Educación Patrimonial Transcompleja, transepistemologías de los saberes y transmetodologías transcomplejas.

melenamate@hotmail.com

ORCID: http://orcid.org/0000-0002-0311-1705 